\title{
Local effect of stereotactic body radiotherapy for primary and metastatic liver tumors in 130 Japanese patients
}

\author{
Hideomi Yamashita ${ }^{*}$, Hiroshi Onishi ${ }^{2}$, Yasuo Matsumoto ${ }^{3}$, Naoya Murakami $^{4}$, Yukinori Matsuo ${ }^{5}$, Takuma Nomiya ${ }^{6}$,
} Keiichi Nakagawa' and Japanese Radiological Society multi-institutional SBRT study group (JRS-SBRTSG)

\begin{abstract}
Background and aims: Stereotactic body radiotherapy (SBRT) is a relatively new treatment for liver tumor. The outcomes of SBRT for liver tumor unfit for ablation and surgical resection were evaluated.

Methods: Liver tumor patients treated with SBRT in seven Japanese institutions were studied retrospectively. Patients given SBRT for liver tumor between 2004 and 2012 were collected. Patients treated with SBRT preceded by trans-arterial chemoembolization (TACE) were eligible. Seventy-nine patients with hepatocellular carcinoma (HCC) and 51 patients with metastatic liver tumor were collected. The median biologically effective dose (BED) ( $\alpha / \beta=10$ Gy) was 96.3 Gy for patients with HCC and 105.6 Gy with metastatic liver tumor.

Results: The median follow-up time was 475.5 days in patients with HCC and 212.5 days with metastatic liver tumor. The 2-year local control rate (LCR) for HCC and metastatic liver tumor was $74.8 \% \pm 6.3 \%$ and $64.2 \pm 9.5 \%(p=0.44)$. The LCR was not different between $B_{E D} D_{10} \geq 100 \mathrm{~Gy}$ and $<100 \mathrm{~Gy}(p=0.61)$. The LCR was significantly different between maximum tumor diameter $>30 \mathrm{~mm}$ vs. $\leq 30 \mathrm{~mm}(64 \%$ vs. 85\%, $p=0.040)$ in all 130 patients. No grade 3 laboratory toxicities in the acute, sub-acute and chronic phases were observed.

Conclusions: There was no difference in local control after SBRT in the range of median BED 10 around 100 Gy for between HCC and metastatic liver tumor. SBRT is safe and might be an alternative method to resection and ablation.

Summary: There was no difference in local control after SBRT in the range of median BED 10 around 100 Gy for between HCC and metastatic liver tumor and SBRT is safe and might be an alternative method to resection and ablation.
\end{abstract}

Keywords: Hepatocellular carcinoma, Metastatic liver tumor, Stereotactic body radiotherapy, Stereotactic ablative radiotherapy

\section{Introduction}

In Japan, an infection rate of the hepatitis $\mathrm{C}$ is high, and there are many hepatocellular carcinoma (HCC) cases. The liver is also a common lesion of metastases from most common solid malignancies. According to clinical practice guidelines from Japan, resection, radiofrequency ablation (RFA), and liver transplantation are the available curative options for HCC [1]. Recently, stereotactic body radiotherapy (SBRT) has become a treatment option for patients

\footnotetext{
* Correspondence: yamachan07291973@yahoo.co.jp

'Department of Radiology, University of Tokyo Hospital, 7-3-1, Hongo,

Bunkyo-ku, Tokyo 113-8655, Japan

Full list of author information is available at the end of the article
}

with liver tumor who are not eligible for surgery, RFA, or liver transplantation. Although HCC doesn't really have bad radiation sensitivity [2], what's happening now is that SBRT for HCC has not been performed very much. One of the reasons is that the role of radiotherapy (RT) for liver tumors has been limited due to the risk of radiationinduced liver disease (RILD) [3]. However, technological advances have made it possible for radiation to be delivered to small liver tumors while reducing the risk of RILD [4]. Resection, RFA, or trance-catheter arterial chemoembolization (TACE) are often performed for HCC and liver metastasis in Japan. However, only $10-20 \%$ of HCC patients have a resectable disease [5]. A drawback to RFA is that 
some anatomic areas make the procedure difficult to perform [6]. It is only the case with a central lesion of the liver, with direct invasion into the vessels, and/or that an effect of TACE was insufficient to be introduced to SBRT. In patients with centrally located HCC with chronic hepatitis or cirrhosis, major resection is often contraindicated due to insufficient residual liver volume [7]. RFA is therefore often contraindicated for HCC in those areas, which are located in and near the hepatic portal vein or central bile duct [8] and abutting the diaphragm [6]. Additionally, the risk of neoplastic seeding along the needle track after RFA has been reported [9].

SBRT offers an alternative, non-invasive approach to the treatment of liver metastasis. The goal of SBRT is to deliver a high dose to the target, thereby providing better local tumor control, while limiting dose to surrounding healthy tissue, thereby potentially decreasing complication rates. Early applications of SBRT to liver metastases have been promising [10-20]. While these data establish the safety of stereotactic radiation therapy for liver metastases, all SBRT treatments must be performed cautiously given the challenges of organ motion and the low radiation tolerance of the surrounding hepatic parenchyma.

Takeda et al. [21] reported that local control rate (LCR) after SBRT for lung metastases from colorectal cancer with a 2-year LCR of $72 \%$ was worse than that for primary lung cancer. We hypothesized that the same thing as this might apply to HCC and liver metastasis and, in other words, LCR after SBRT for liver metastases might be worse than that for HCC.

Because there was little number of cases that has performed liver SBRT in every each institution, we wanted to research results and a side effect as a whole in many institutions. The purpose of this study was to retrospectively evaluate the outcomes, mainly concerning local control, of patients treated at various dose levels in many Japanese institutions.

\section{Materials and methods Patients}

This is a retrospective study to review 130 patients with primary or metastatic liver cancers treated at seven institutions extracted from the database of Japanese Radiological Society multi-institutional SBRT study group (JRS-SBRTSG). The investigation period was from May 2004 to November 2012.

The diagnosis of HCC depended mostly on imaging studies, because candidates for SBRT were unfeasible for pathological confirmation. During follow-up of patients with liver disease, nodules $\geq 1 \mathrm{~cm}$ were diagnosed as HCC based on the typical hallmarks (hyper-vascular in the arterial phase with washout in the portal, venous or delayed phases) from imaging studies, which included a combination of contrast-enhanced ultrasonography, 4-phase multi-detector computed tomography (CT), dynamic contrast-enhanced magnetic resonance imaging (MRI), and CT during hepatic arteriography and arterio-portography studies. The diagnosis was established according to a review [22] and clinical practice guidelines [23,24]. The eligibility of SBRT for HCC was a single lesion in principle.

The diagnosis of metastatic liver tumor was confirmed by diagnostic imaging including ultrasound, CT, and/or MRI. The eligibility of SBRT for metastatic liver tumor was without other lesions and in less than four.

Patient and tumor characteristics were shown in Table 1. HCC included 79 cases and the liver metastases included 51 cases. The Child-Pugh score before SBRT for $\mathrm{HCC}$ was $84.8 \%$ in grade A, $11.4 \%$ in grade B, and $1.3 \%$ in grade C. Ischemic HCC was $16 / 79$ cases $(20 \%)$ and plethoric HCC was 55/79 cases (70\%). The median alpha-fetoprotein (AFP) (ng/mL) and des-gamma carboxy prothrombin (PIVKA-II) (AU/mL) value before SBRT for evaluable 73 patients with HCC were 12.7 (range; 0.8-8004) and 35 (range; 3.1-16900). The median indocyanine green retention rate at $15 \mathrm{~min}$ (ICG15) value before SBRT for evaluable 25 patients with HCC was $21.2 \%$ (range; $3-56.2 \%$ ). This SBRT was the first treatment in $26 / 79$ cases (33\%) and was the first treatment about the same lesion as this SBRT in the additional 7 cases. About the primary tumor site of liver metastases, colo-rectum was $58.8 \%$, lung was $9.8 \%$, and stomach was $9.8 \%$. The number of SBRT lesions was from 1 to 4 (solitary was 41/51 cases) for liver metastasis.

\section{Treatment}

For treatment planning, abdominal pressure corsets such as body shell or vacuum cushion such as blue back were used, and it was confirmed that tumor motion was $<1 \mathrm{~cm}$. Then, the gross tumor volume (GTV) was delineated on the both inspiratory and expiratory planning CT images in the case of respiratory depression method. The breathholding method was used in 36 cases, gating method in 10 cases, and respiratory depression method in 25 cases about HCC patients. The planning target volume (PTV) was configured considering respiratory movement, a set-up margin, and a sub-clinical margin (Figure 1). SBRT was performed with an X-ray beam linear accelerator of $6 \mathrm{MV}$. The total dose was delivered depending on judgment each institution. A collapsed cone (CC) convolution, superposition algorithm, or analytical anisotropic algorithm (AAA) was used for dose calculations.

The mode value of total irradiated dose was $48 \mathrm{~Gy}$ in 4 fractions (38/79 cases) (from 40 Gy in 4 fractions to 60 Gy in 10 fractions) for HCC and 48 Gy in 4 fractions (12/51 cases) and 52 Gy in 4 fractions (16/51 cases) (from $30 \mathrm{~Gy}$ in 3 fractions to $60 \mathrm{~Gy}$ in 8 fractions) for metastatic liver tumor. The biologically effective dose 
Table 1 Patient and tum or characteristics of SBRT

\begin{tabular}{|c|c|c|c|c|c|c|}
\hline Liver metastasis & $\mathrm{N}$ & $\%$ & $\mathrm{HCC}$ & & $\mathrm{N}$ & $\%$ \\
\hline & 51 & 100 & & & 79 & 100 \\
\hline Primary cancer & & & Stage & & & \\
\hline Colon cancer & 21 & 41.2 & & I & 29 & 36.7 \\
\hline Rectal cancer & 9 & 17.6 & & $\|$ & 21 & 26.6 \\
\hline Lung cancer & 5 & 9.8 & & III & 5 & 6.3 \\
\hline Gastric cancer & 5 & 9.8 & & IV & 2 & 2.5 \\
\hline Cervical cancer & 3 & 5.9 & & Recurrence & 11 & 13.9 \\
\hline Breast cancer & 3 & 5.9 & & $\mathrm{NE}$ & 11 & 13.9 \\
\hline Pancreatic cancer & 3 & 5.9 & & & & \\
\hline Bile duct cancer & 1 & 2.0 & & & & \\
\hline Skin cancer & 1 & 2.0 & & & & \\
\hline Number of SRT & & & & $\begin{array}{l}\text { Chilid-Pugh } \\
\text { before SBRT }\end{array}$ & & \\
\hline Single SRT & 41 & 80.4 & & A & 67 & 84.8 \\
\hline Two places & 8 & 15.7 & & B & 9 & 11.4 \\
\hline Tree & 1 & 2.0 & & C & 1 & 1.3 \\
\hline Four & 1 & 2.0 & & $\mathrm{NE}$ & 2 & 2.5 \\
\hline \multicolumn{7}{|l|}{ Sex } \\
\hline Female & 17 & 33.3 & & & 19 & 24 \\
\hline Male & 34 & 66.7 & & & 60 & 75.9 \\
\hline \multicolumn{7}{|l|}{ Tumor diameter (mm) } \\
\hline Range & $13-54$ & & & & $6-70$ & \\
\hline Median & 26 & & & & 27 & \\
\hline \multicolumn{7}{|l|}{$\begin{array}{l}\text { Performance status } \\
\text { (ECOG) }\end{array}$} \\
\hline 0 & 32 & 62.7 & & & 34 & 43.0 \\
\hline 1 & 13 & 25.5 & & & 39 & 49.4 \\
\hline 2 & 5 & 9.8 & & & 4 & 5.1 \\
\hline 3 & 1 & 2.0 & & & 1 & 1.3 \\
\hline \multicolumn{7}{|l|}{ Age (years old) } \\
\hline Range & $33-90$ & & & & $38-95$ & \\
\hline Median & 73 & & & & 73 & \\
\hline \multicolumn{7}{|l|}{ SRT total dose (Gy) } \\
\hline Range & $30-60$ & & & & $40-60$ & \\
\hline Median & 50 & & & & 48 & \\
\hline \multicolumn{7}{|l|}{ BED-10 (Gy) } \\
\hline Range & $56-134.4$ & & & & $75-106$ & \\
\hline Median & 105.6 & & & & 96.3 & \\
\hline
\end{tabular}

Abbreviation: NE not evaluable.

(BED) $(\alpha / \beta=10$ Gy) was 75-106 Gy (median: 96 Gy) for patients with HCC and 56-134 Gy (median: 106 Gy) with metastatic liver tumor (Table 1). The formula about $\mathrm{BED}_{10}$ was used; $\mathrm{BED}\left(\mathrm{Gy}_{10}\right)=$ nd $(1+\mathrm{d} / \alpha / \beta)$. In all 130 cases, CT registration like cone beam CT was performed each treatment.
SBRT was delivered using multiple non-coplanar static beams (using $>7$ non-coplanar fields) generated by a linear accelerator or volumetric modulated arc therapy. Daily image guidance, by using either orthogonal X-rays or onboard CT imaging, was used to re-localize the target before treatment delivery.

Trans-catheter arterial chemoembolization (TACE) in 7 HCC patients, FOLFILI regimen (folinic acid, fluorouracil, plus irinotecan) in a metastatic liver tumor patient, or TAXOL $^{\bullet}$ (paclitaxel) in a metastatic liver tumor patient was performed before SBRT. Oral TS-1 was combined concurrently with SBRT in an HCC patient.

\section{Follow up}

Patients were seen monthly for 1 year after SBRT and trimonthly thereafter. Laboratory tests were done at every visit. Treatment responses and intrahepatic recurrences were evaluated with dynamic contrast-enhanced CT or MRI every 3 months with modified Response Evaluation Criteria in Solid Tumors (mRECIST) [25]. Toxicity was evaluated with the Common Terminology Criteria for Adverse Events (CTCAE), version 4.0. Acute and sub-acute toxicities were defined as adverse events occurring within 3 months and 3-6 months, respectively, after SBRT. Late toxicities related with liver and other toxicities were defined as those occurring after 6-12 months and from 6 months to last follow-up, respectively. Laboratory tests included aspartate aminotransferase, total bilirubin, platelet count, and albumin.

Local recurrence was defined as progressive disease in mRECIST or the new appearance of a lesion within the PTV, and local control was defined as free of local recurrence. Local control was defined as freedom from local progression by mRECIST.

\section{Statistical analysis}

Control and survival rates were calculated with KaplanMeier analysis. Log-rank testing was used to compare outcomes between the subsets of patients analyzed. Cox proportional hazards regression analysis was used for multivariate analysis. A $p$-value of $<0.05$ was considered significant. Data were analyzed with SPSS Statistics 20.0 (IBM Corp., Armonk, NY, USA). The points on survival curves by Kaplan Meier are a censored case.

\section{Results}

\section{Eligible patients}

The median follow-up time was 475.5 days (range; 101-2050 days) in patients with HCC and 212.5 days (range; 26-2713 days) with metastatic liver tumor. SBRT was performed as scheduled and was feasible in all patients. At the last follow-up, 48/79 cases (61\%) were survival and 31/79 (39\%) were dead for HCC and 42/51 


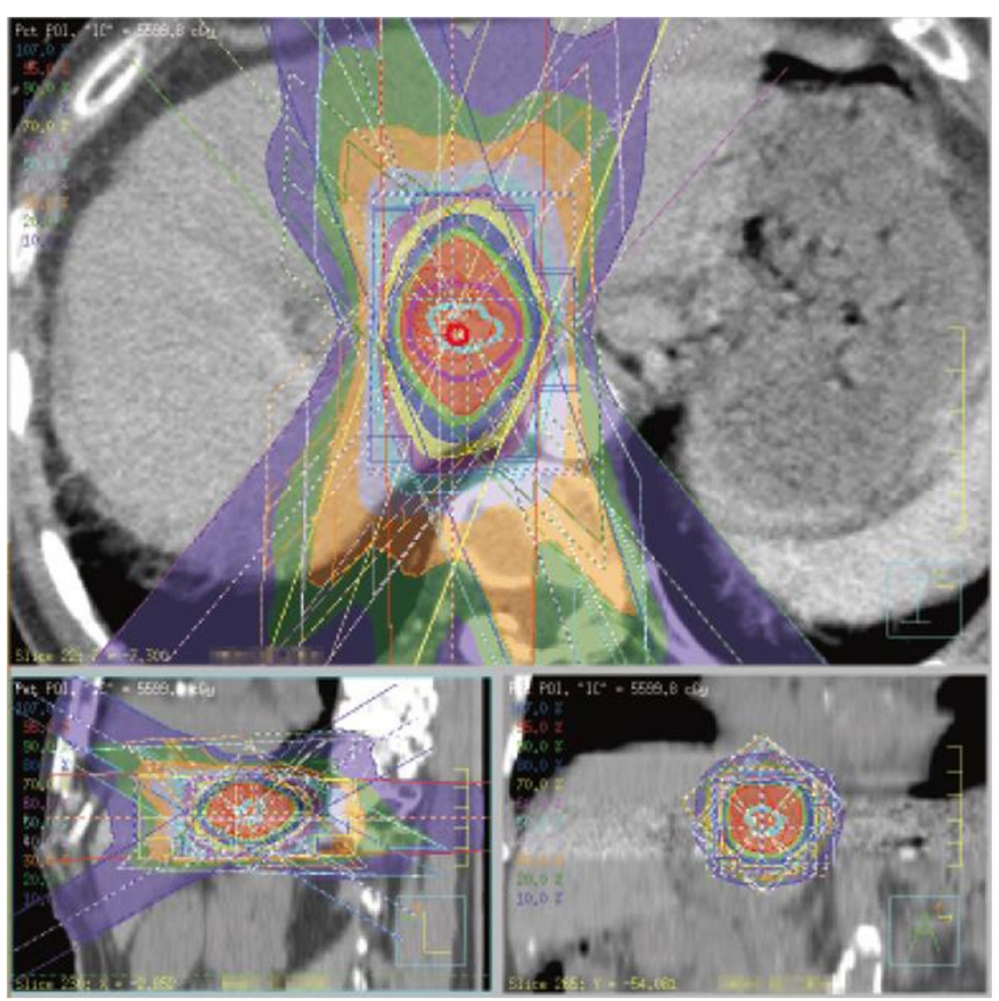

Figure 1 Dose distribution of SBRT for liver tumor. Sky blue line $=$ ITV, purple line $=$ PTV, red area $=$ over 95\% dose, green area $=90-95 \%$, blue area $=80-90 \%$, yellow area $=70-80 \%$, purple area $=60-70 \%$, sky blue area $=50-60 \%$, orange area $=30-40 \%$.

cases $(82 \%)$ were survival and 9/51 cases (18\%) were dead for metastatic liver tumors.

\section{Treatment outcomes}

Clinical results were shown in Table 2. As to the initial local effect, complete response (CR) and partial response

Table 2 Clinical results of SBRT

\begin{tabular}{cccccc}
\hline & \multicolumn{2}{c}{$\mathbf{N}$} & & $\mathbf{N}$ & $\%$ \\
\cline { 2 - 3 } \cline { 5 - 6 } & \multicolumn{2}{c}{ Liver metastasis } & & HCC \\
\hline First local effect & & & & \\
CR & 15 & 29.4 & & 36 & 45.6 \\
PR & 23 & 45.1 & & 28 & 35.4 \\
MR & 2 & 3.9 & & 0 & 0 \\
NC & 6 & 11.8 & & 9 & 11.4 \\
PD & 0 & 0 & & 4 & 5.1 \\
NE & 5 & 9.8 & & 2 & 2.5 \\
Local progress & 10 & & & \\
With & 37 & 72.5 & 63 & 79.7 \\
Without & 4 & 7.8 & 2 & 2.5 \\
NE & & 19.6 & & 14 & 17.7 \\
\hline
\end{tabular}

Abbreviation: $C R$ complete response, $P R$ partial response, $M R$ minor response, $N C$ no change, $P D$ progress disease, $N E$ not evaluable.
(PR) were $45.6 \%$ and $35.4 \%$ in SBRT for HCC and $29.4 \%$ and $45.1 \%$ for metastatic liver tumor, respectively.

The 2-year cumulative LCR for HCC and metastatic liver tumor was $74.8 \% \pm 6.3 \%$ (standard error) and $64.2 \pm 9.5 \%$ $(p=0.44)$ (Figure 2). The LCR was not different between $\mathrm{BED}_{10} \geq 100$ Gy $(69.0 \% \pm 7.6 \%$ at 2 years $)$ vs. $<100$ Gy $(72.4 \% \pm 7.7 \%)$ in all 130 patients $(p=0.61)$ (Figure 3$)$. The LCR was not different between HCC $(68.2 \% \pm 11.2 \%)$ vs. liver metastasis $(68.3 \% \pm 11.2 \%)$ in 70 patients with the higher $\mathrm{BED}_{10} \geq 100 \mathrm{~Gy}(p=0.96)$. The LCR was not different between $\mathrm{BED}_{10} \geq 100$ Gy $(68.3 \% \pm 11.2 \%)$ vs. $<100 \mathrm{~Gy}$ $(46.5 \% \pm 16.9 \%)$ in 51 patients with liver metastasis $(68.2 \% \pm 11.2 \%$ vs. $79.2 \% \pm 7.7 \%, p=0.72)$ and in 79 patients with $\mathrm{HCC}(p=0.43)$. In all 130 patients, the LCR was not different between maximum tumor diameter $>20 \mathrm{~mm}$ vs. $\leq 20 \mathrm{~mm}(70.6 \% \pm 7.6 \%$ vs. $83.5 \% \pm$ $7.6 \%, p=0.28)$ and $\geq 40 \mathrm{~mm}$ vs. $<40 \mathrm{~mm}(55.4 \% \pm 17.2 \%$ vs. $79.8 \% \pm 5.1 \%, p=0.32$ ) except for $>30 \mathrm{~mm}$ vs. $\leq 30 \mathrm{~mm}$ $(64.1 \% \pm 9.1 \%$ vs. $85.2 \% \pm 5.6 \%, p=0.040)$ (Figure 4$)$. The LCR was not different between $\mathrm{BED}_{10} \geq 100 \mathrm{~Gy}$ $(66.2 \% \pm 33.8 \%)$ vs. $<100$ Gy $(62.3 \% \pm 12.6 \%)$ in 41 patients with the bigger tumor diameter $>30 \mathrm{~mm}(p=$ 0.78). The LCR was not different between older ( $>70$ y.o.) vs. younger $(\leq 70$ y.o. $)(74.4 \% \pm 6.2 \%$ vs. $70.6 \% \pm 8.9 \%$, $p=0.76)$. 


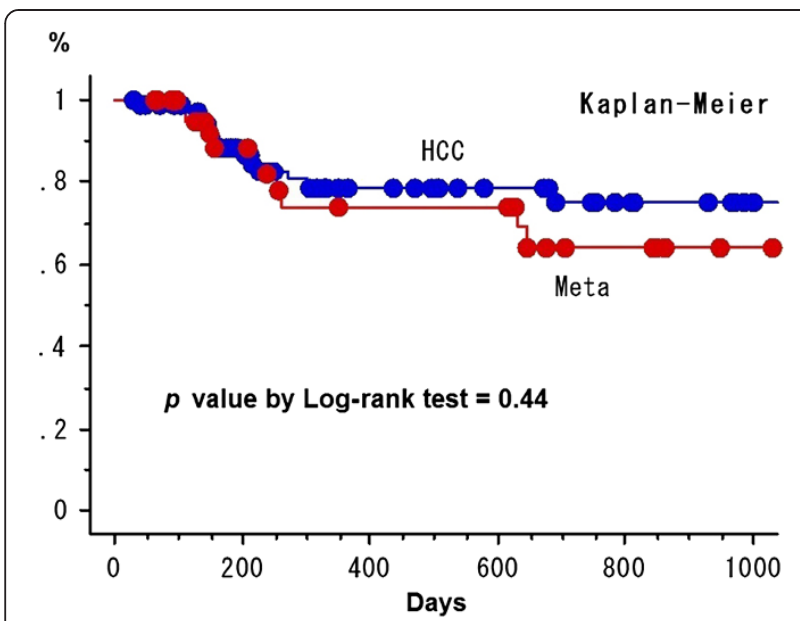

Figure 2 Local control curves between SBRT for hepatic cell carcinoma and metastatic liver tumor. The points on survival curves are a censored case.

By multivariate analysis (Cox proportional hazards regression analysis), the maximum tumor diameter $>$ $30 \mathrm{~mm}$ vs. $\leq 30 \mathrm{~mm}$ (other covariates were $\mathrm{BED}_{10} \geq$ 100 Gy vs. $<100$ Gy of $p=0.70$, age $>70$ y.o. vs. $\leq 70$ y.o. of $p=0.73$, HCC vs. metastatic liver tumor of $p=0.52$ ) was the only significant factor for LCR $(p=0.047,95 \% \mathrm{CI}=$ 1.014-7.546).

The scatter diagram between $\mathrm{BED}_{10}$ and local control time was shown in Figure 5. There was no correlation between $\mathrm{BED}_{10}$ and local control time. We didn't show the fact that the higher $\mathrm{BED}_{10}$ was, the longer local control time was.

The 2-year overall survival (OS), cause specific survival (CSS), disease free survival (DFS), and distant metastatic free survival (DMF) were $52.9 \% \pm 7.1 \%, 69.0 \% \pm 6.9 \%$, $39.9 \% \pm 6.9 \%$, and $76.3 \% \pm 6.6 \%$ in 79 patients with HCC, respectively (Figure 6). The number of patients at risk was

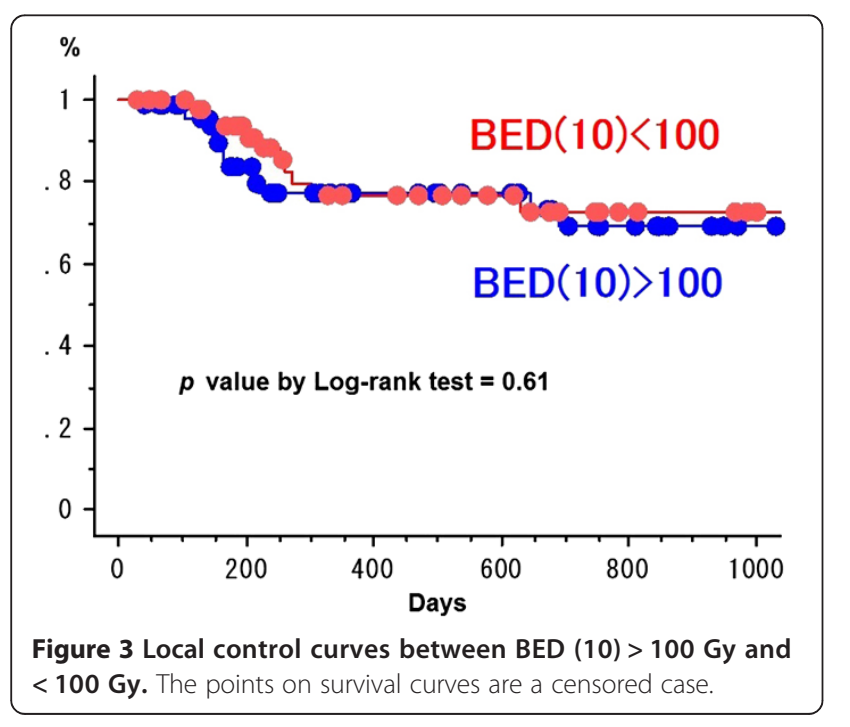

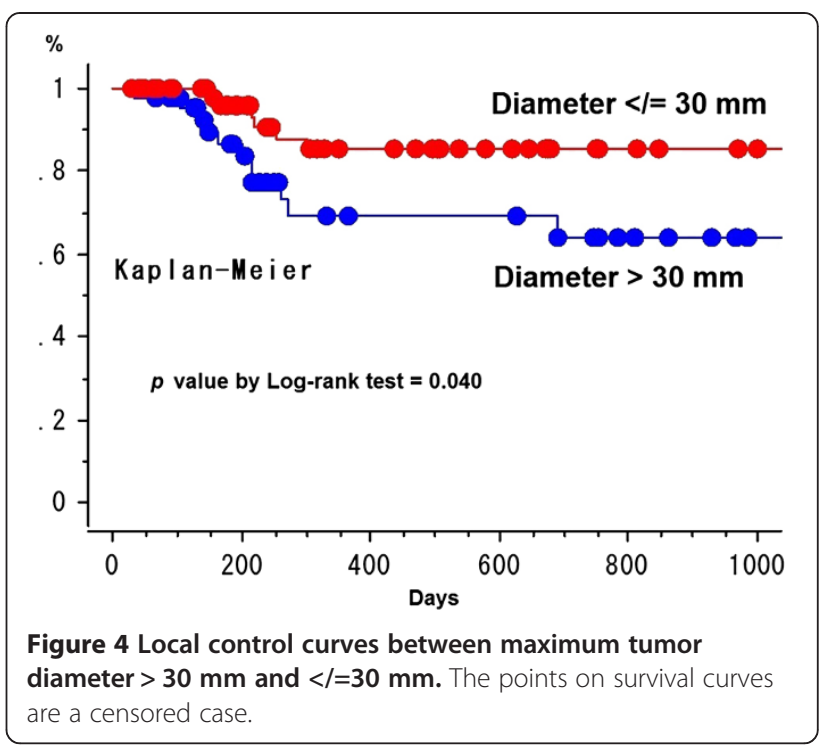

43, 21, 9, and 3 at 1-, 2-, 3-, and 4-year in OS, respectively. The 2 -year OS was $71.9 \% \pm 9.4 \%$ in 51 patients with metastatic liver tumor.

The 2-year cumulative LCR for HCC $(\mathrm{n}=79)$ vs. metastatic liver tumor from colorectal cancer $(\mathrm{n}=30)$ vs. from other cancers $(\mathrm{n}=21)$ was $74.1 \% \pm 6.2 \%$ vs. $54.2 \% \pm 11.8 \%$ vs. $87.5 \% \pm 11.7 \%$ ( $p=0.18$ by comparison among three groups, $p=0.12$ between colorectal and other cancers, and $p=0.16$ between HCC and colorectal cancer).

\section{Treatment-related toxicity}

All SBRT were completed without toxicity during RT period. There was no Grade 5 toxicity. Nine patients (7\%) experienced Grade 2-4 gastrointestinal toxicity. Three patients had Grade 2 gastric inflammations at both $1 \mathrm{Mo}$ (40 Gy in 4 fractions and 60 Gy in 10 fractions) and one gastric ulcer at 27 Mo (60 Gy in 10 fractions). Four had Grade 3 intestinal tract bleedings at $5 \mathrm{Mo}$ (50 Gy in 5 fractions) and 6 Mo (40 Gy in 4 fractions) and transverse colon ulceration at $5 \mathrm{Mo}$ (60 Gy in 10 fractions) and duodenal ulcer at 17 Mo (48 Gy in 4 fractions) without chemotherapy in all 4 cases. One patient had Grade 4 gastro-duodenal artery rupture at 6 Mo after SBRT of $48 \mathrm{~Gy}$ in 4 fractions without chemotherapy. One patient complained of chest wall pain after SBRT of 45.2 Gy in 4 fractions combined with TACE.

No significant ( $\geq$ grade 3 ) liver enzyme elevation was observed during treatment. No classic RILD was observed.

\section{Discussion}

This is a retrospective study to review 130 patients with primary or metastatic liver cancers treated at 20 institutions extracted from the database of JRS-SBRTSG. The primary aim of the paper is to report outcome in terms 


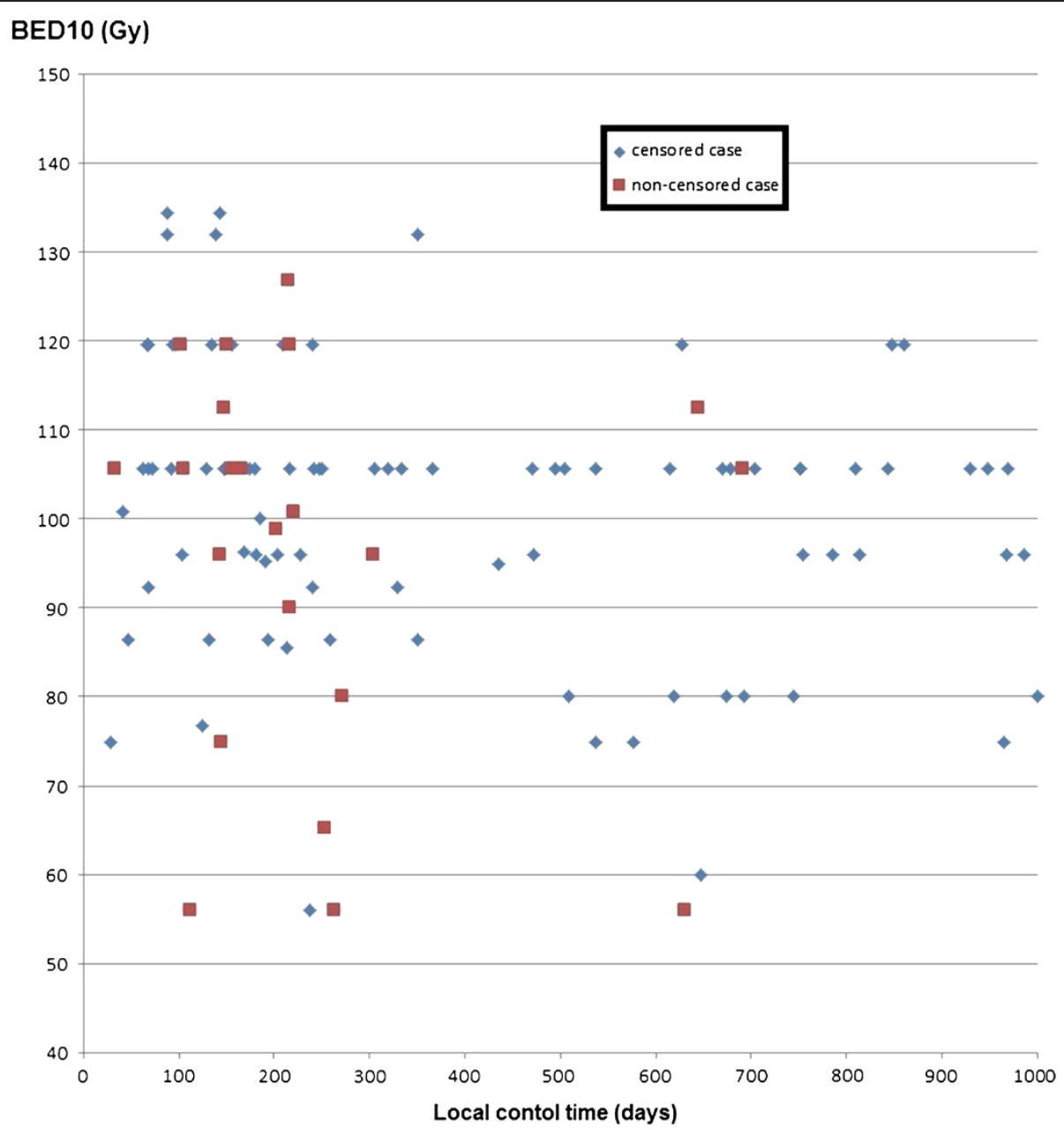

Figure 5 Scatter diagram between BED10 (Gy) and local control time (days).

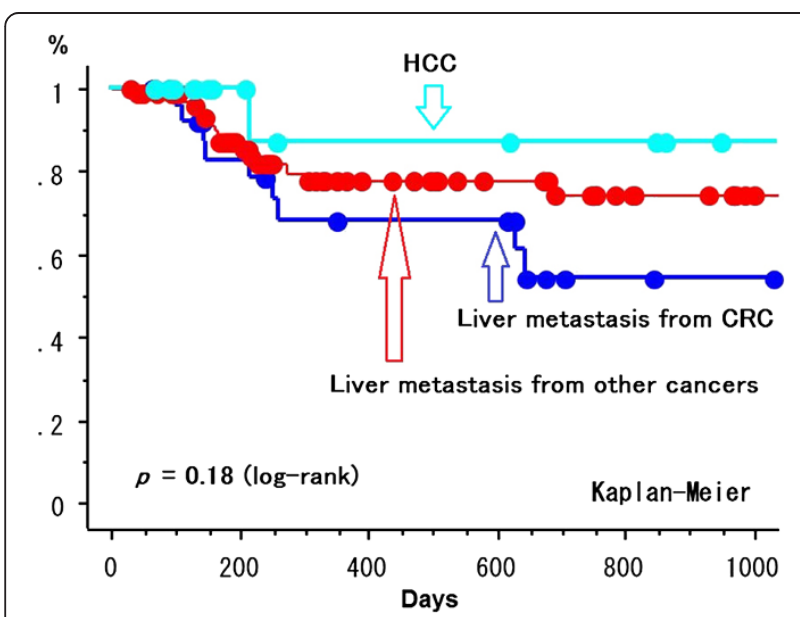

Figure 6 Local control curves among HCC, liver metastases from colorectal cancer, and from other cancers. of survival, local control, and toxicity. Overall survivals in this study of $53 \%$ for HCC $(n=79)$ and $72 \%$ for liver metastases $(n=51)$ at 2 year after SBRT were almost satisfactory (median follow-up was 16 months), but there were various biases in that the candidates included frail patients contraindicated due to decompensated cirrhosis and older patients with a median age of 73 years. It was the reason why only LCR was performed for the factor analysis in this study.

The local controls after stereotactic body radiotherapy for liver tumor were $65 \%$ to $100 \%$ in HCC and $56 \%$ to $100 \%$ in metastatic liver tumor. Results of phase I/II studies and retrospective series of SBRT for HCC patients indicated high local control rates of $90-100 \%$ [26-29]. In this study, local recurrence was seen at within 8 months in almost all cases and at 20 to 23 months in some cases. The LCR of HCC in this study was slightly poor and could hardly have been more different from that of metastatic liver tumor. We showed the summary of LC after SBRT for liver tumor in Table 3. 
Table 3 Summary of local control after stereotactic body radiotherapy for liver tumor

\begin{tabular}{|c|c|c|c|c|c|c|c|c|}
\hline First author & Ref. & Target & Year & Case no. & Total RT dose & Fr no. & LC & Timing of LC \\
\hline Blomgren $\mathrm{H}$ & {$[30]$} & $\mathrm{HCC}$ & 1995 & 20 & 15-45 Gy & $1-5$ & $80 \%$ & $1.5-38 \mathrm{mo}$ \\
\hline Tse RV & {$[26]$} & $\mathrm{HCC} \& \mathrm{IHC}$ & 2008 & 41 & 36 Gy & 6 & $65 \%$ & $12 \mathrm{mo}$ \\
\hline Cardenes HR & {$[31]$} & $\mathrm{HCC}$ & 2010 & 17 & 36-48 Gy & 3 & $100 \%$ & $10-42 \mathrm{mo}$ \\
\hline Kwon JH & [32] & $\mathrm{HCC}$ & 2010 & 42 & 30-39 Gy & 3 & $68 \%$ & $36 \mathrm{mo}$ \\
\hline Louis C & [33] & $\mathrm{HCC}$ & 2010 & 25 & 45 Gy & 3 & $95 \%$ & $24 \mathrm{mo}$ \\
\hline Seo YS & {$[34]$} & $\mathrm{HCC}$ & 2010 & 38 & 33-57 Gy & $3-4$ & $66 \%$ & $24 \mathrm{mo}$ \\
\hline \multirow[t]{2}{*}{ Andolino DL } & {$[28]$} & $\mathrm{HCC}$ & 2011 & 60 & 40 Gy, 44 Gy & 5 & $90 \%$ & $24 \mathrm{mo}$ \\
\hline & & & & & & 3 & & \\
\hline Kang JK & {$[29]$} & $\mathrm{HCC}$ & 2012 & 50 & $42-60 \mathrm{~Gy}$ & 3 & $95 \%$ & $24 \mathrm{mo}$ \\
\hline Takeda A & {$[21]$} & $\mathrm{HCC}$ & 2013 & 63 & 35-40 Gy & 5 & $92 \%$ & $36 \mathrm{mo}$ \\
\hline Herfarth KK & {$[10]$} & $M L$ & 2001 & 37 & $14-26$ Gy & $N A$ & $78 \%$ & $5.7 \mathrm{mo}$ \\
\hline Wada H & [11] & $M L$ & 2004 & 34 & 45 Gy & 3 & $86 \%$ & $12 \mathrm{mo}$ \\
\hline Kavanagh BD & [12] & $M L$ & 2006 & 36 & 60 Gy & 3 & $93 \%$ & $18 \mathrm{mo}$ \\
\hline Hoyer M & [13] & $M L$ & 2006 & 64 & 45 Gy & 3 & $63 \%$ & $24 \mathrm{mo}$ \\
\hline Katz AW & [14] & $M L$ & 2007 & 69 & 30-55 Gy & $N A$ & $57 \%$ & $20 \mathrm{mo}$ \\
\hline Lee MT & {$[16]$} & $M L$ & 2009 & 68 & 27.7-60 Gy & 6 & $71 \%$ & $12 \mathrm{mo}$ \\
\hline Rusthoven KE & [17] & $M L$ & 2009 & 47 & 36-60 Gy & 3 & $92 \%$ & $24 \mathrm{mo}$ \\
\hline \multirow[t]{3}{*}{ Rule W } & [18] & $M L$ & 2011 & 27 & 30 Gy, & 3 & $56 \%$ & $24 \mathrm{mo}$ \\
\hline & & & & & $50 \mathrm{~Gy}$, & 5 & $89 \%$ & \\
\hline & & & & & 60 Gy & 5 & $100 \%$ & \\
\hline Chang DT & [19] & $M L$ & 2011 & 65 & 46-52 Gy & 3 & $90 \%$ & $12 \mathrm{mo}$ \\
\hline Fumagalli I & {$[20]$} & $M L$ & 2012 & 90 & $15 \mathrm{~Gy}$ & 3 & $66 \%$ & $24 \mathrm{mo}$ \\
\hline
\end{tabular}

Abberiviation: $H C C$ hepatocellular carcinoma, IHC intrahepatic cholangiocarcinoma, $M L$ metastatic liver tumor, $R T$ radiotherapy, $\mathrm{Fr}=\mathrm{fractions}, \mathrm{LC}=$ local control, mo months.

LCR might be overestimated using cumulative LCR like the present report because patients who died without the evidence of local recurrence were excluded. Since the pure LCR want to be calculated, the patients who died without local recurrence were treated as a censored case. Takeda et al. [21] reported that LCR after SBRT for lung metastases from colorectal cancer with a 2 -year LCR of $72 \%$ was worse than that for primary lung cancer and also in the present study, LCR for liver metastases from colorectal cancer was slightly worse than that for HCC or liver metastases from other cancers, although there was no significant difference. The patient number at this time may be too small to detect the significant differences on LCR among three groups.

To improve our results of local control and so on, we may increase radiation dose. The median $\mathrm{BED}_{10}$ in this study was 96 Gy for patients with HCC and 106 Gy with metastatic liver tumor. Although it is natural that $\mathrm{BED}_{10}$ is over 100 Gy in the SBRT for lung tumor, the fact may be not true of the SBRT for liver tumor. Although the aim of SBRT is to deliver a high ablative dose to destroy tumor cells, the optimal treatment dose should be determined based on both tumor control and long-term safety because radiation damage to the normal liver tissue is dose-volume-dependent $[35,36]$. In SBRT for liver tumors, the prescribed dose and fraction vary across studies, ranging from 24-60 Gy in 2-6 fractions, and most studies focused predominantly on liver metastases [37]. Since metastatic lung tumors require dose escalation due to relatively low radio-sensitivity [38], increasing the dose to metastatic liver tumors appears to be reasonable, and patients with normal liver function treated with SBRT have rarely developed RILD. In contrast, dose escalation in HCC patients with decompensated cirrhotic liver disease may be disadvantageous with respect to normal liver tolerance. A dose-control relationship has been described for patients treated with SBRT for liver and lung metastases. In an analysis of 246 lesions treated with three-fraction SBRT for primary or metastatic tumors within the lung or liver, McCammon et al. [39] demonstrated significant improvement in local control with increasing dose and the 3 -year local control rate in their series was $89.3 \%$ for those lesions that received 54 to 60 Gy versus $59 \%$ and $8.1 \%$ for lesions that received 36 to 53.9 Gy and less than $36 \mathrm{~Gy}$, respectively $(p<0.01)$. Tekeda et al. [40] used 35-40 Gy in 5 fractions based on baseline liver function and liver 
volume receiving $\geq 20$ Gy of SBRT for untreated solitary HCC patients.

By multivariate analysis, the maximum tumor diameter $>30 \mathrm{~mm}$ vs. $\leq 30 \mathrm{~mm}$ was only one prognostic factor for LCR. According to Rusthoven et al. [17], actuarial in-field local control rates at one \& two years after SBRT of 60 Gy in 3 fractions for the treatment of 47 patients with one to three hepatic metastases (63 lesions) were $95 \%$ \& $92 \%$ and 2-year local control was $100 \%$ among lesions with maximal diameter of $3 \mathrm{~cm}$ or less.

However, this study has some limitations in that it is a retrospective and multi-institutional series with a relatively short follow-up period. The group is very heterogeneous including primary and metastatic liver tumors. That is why the irradiated dose and the follow-up method are inconsistent, too. The reason why there was no difference by the stratification of irradiated dose may be that in this study the problem of algorithm or prescription point can be integrated. We are planning to start a multi-institutional prospective large-scale clinical trial that standardized these factors.

\section{Conclusions}

There was no difference in LCR between liver metastasis vs. $\mathrm{HCC}$ and the higher vs. lower $\mathrm{BED}_{10}$ against SBRT for liver cancer except for the bigger vs. smaller tumor diameter. SBRT is a safe treatment and may be an alternative option for patients with liver tumor unfit for resection or RFA. Further prospective studies are warranted to validate the effect of SBRT for liver tumor.

\section{Competing interests}

The authors have no conflict of interest to disclose with respect to this presentation.

\section{Authors' contributions}

$\mathrm{HY}$ and $\mathrm{HO}$ carried out the molecular genetic studies, participated in the sequence alignment and drafted the manuscript. YM, NM, YM, TN, and TK were gave clinical data in their own institution and corrected the manuscript. KN corrected the manuscript. All authors read and approved the final manuscript.

\section{Author details \\ 'Department of Radiology, University of Tokyo Hospital, 7-3-1, Hongo, Bunkyo-ku, Tokyo 113-8655, Japan. '2Department of Radiology, University of Yamanashi, Yamanashi, Japan. ${ }^{3}$ Department of Radiology, Niigata Cancer Center Hospital, Niigata, Japan. ${ }^{4}$ Department of Radiation Oncology, National Cancer Center Hospital, Singapore, Singapore. ${ }^{5}$ Department of Radiation Oncology and Image-applied Therapy, Graduate School of Medicine, Kyoto University, Kyoto, Japan. ${ }^{6}$ Department of Radiation Oncology, Yamagata University Hospital, Yamagata, Japan.}

Received: 20 January 2014 Accepted: 21 April 2014 Published: 10 May 2014

\section{References}

1. Arii S, Sata M, Sakamoto M, Shimada M, Kumada T, Shiina S, Yamashita T, Kokudo N, Tanaka M, Takayama T, Kudo M: Management of hepatocellular carcinoma: Report of Consensus Meeting in the 45th Annual Meeting of the Japan Society of Hepatology (2009). Hepatol Res 2010, 40:667-685.
2. Yamashita H, Nakagawa K, Shiraishi K, Tago M, Igaki H, Nakamura N, Sasano N, Siina S, Omata M, Ohtomo K: Radiotherapy for lymph node metastases in patients with hepatocellular carcinoma: retrospective study. J Gastroenterol Hepatol 2007, 22:523-527.

3. Garrean S, Hering J, Saied A, Helton WS, Espat NJ: Radiofrequency ablation of primary and metastatic liver tumors: a critical review of the literature. Am J Surg 2008, 195:508-520.

4. Dawson LA, Normolle D, Balter JM, McGinn CJ, Lawrence TS, Ten Haken RK Analysis of radiation-induced liver disease using the Lyman NTCP model. Int J Radiat Oncol Biol Phys 2002, 53:810-821.

5. Ikai I, Arii S, Okazaki M, Okita K, Omata M, Kojiro M, Takayasu K, Nakanuma Y, Makuuchi M, Matsuyama Y, Monden M, Kudo M: Report of the 18th follow-up survey of primary liver cancer in Japan. Hepatol Res 2010, 40:1043-1059.

6. Rhim H, Lim HK: Radiofrequency ablation for hepatocellular carcinoma abutting the diaphragm: the value of artificial ascites. Abdom Imaging 2009, 34:371-380.

7. Torzilli G, Makuuchi M, Inoue K, Takayama T, Sakamoto $Y$, Sugawara $Y$, Kubota K, Zucchi A: No-mortality liver resection for hepatocellular carcinoma in cirrhotic and noncirrhotic patients: is there a way? A prospective analysis of our approach. Arch Surg 1999, 134:984-992.

8. Lin SM, Lin CJ, Lin CC, Hsu CW, Chen YC: Randomised controlled trial comparing percutaneous radiofrequency thermal ablation, percutaneous ethanol injection, and percutaneous acetic acid injection to treat hepatocellular carcinoma of $3 \mathrm{~cm}$ or less. Gut 2005, 54:1151-1156.

9. Yamashita H, Nakagawa K, Shiraishi K, Tago M, Igaki H, Nakamura N, Sasano $N$, Shiina S, Omata M, Ohtomo K: External beam radiotherapy to treat intra- and extra-hepatic dissemination of hepatocellular carcinoma after radiofrequency thermal ablation. J Gastroenterol Hepatol 2006, 21:1555-1560.

10. Herfarth KK, Debus J, Lohr F, Bahner ML, Rhein B, Fritz P, Höss A, Schlegel W, Wannenmacher MF: Stereotactic single-dose radiation therapy of liver tumors: results of a phase I/II trial. J Clin Oncol 2001, 19(1):164-170.

11. Wada H, Takai Y, Nemoto K, Yamada S: Univariate analysis of factors correlated with tumor control probability of three-dimensional conformal hypofractionated high-dose radiotherapy for small pulmonary or hepatic tumors. Int J Radiat Oncol Biol Phys 2004, 58(4):1114-1120.

12. Kavanagh BD, Schefter TE, Cardenes HR, Stieber WW, Raben D, Timmerman RD, McCarter MD, Burri S, Nedzi LA, Sawyer TE, Gaspar LE: Interim analysis of a prospective phase I/II trial of SBRT for liver metastases. Acta Oncol 2006, 45(7):848-855.

13. Hoyer M, Roed H, Traberg Hansen A, Ohlhuis L, Petersen J, Nellemann H, Kii Berthelsen A, Grau C, Aage Engelholm S, Von der Maase H: Phase II study on stereotactic body radiotherapy of colorectal metastases. Acta Oncol 2006, 45(7):823-830.

14. Katz AW, Carey-Sampson M, Muhs AG, Milano MT, Schell MC, Okunieff P: Hypofractionated stereotactic body radiation therapy (SBRT) for limited hepatic metastases. Int J Radiat Oncol Biol Phys 2007, 67(3):793-798.

15. Goodman KA, Wiegner EA, Maturen KE, Zhang Z, Mo Q, Yang G, Gibbs IC, Fisher GA, Koong AC: Dose-escalation study of single-fraction stereotactic body radiotherapy for liver malignancies. Int J Radiat Oncol Biol Phys 2010, 78(2):486-493.

16. Lee MT, Kim JJ, Dinniwell R, Brierley J, Lockwood G, Wong R, Cummings B, Ringash J, Tse RV, Knox JJ, Dawson LA: Phase I study of individualized stereotactic body radiotherapy of liver metastases. J Clin Oncol 2009, 27:1585-1591.

17. Rusthoven KE, Kavanagh BD, Cardenes H, Stieber WW, Burri SH, Feigenberg SJ, Chidel MA, Pugh TJ, Franklin W, Kane M, Gaspar LE, Schefter TE: Multiinstitutional phase I/II trial of stereotactic body radiation therapy for liver metastases. J Clin Oncol 2009, 27:1572-1578.

18. Rule W, Timmerman R, Tong L, Abdulrahman R, Meyer J, Boike T, Schwarz RE, Weatherall P, Chinsoo Cho L: Phase I dose-escalation study of stereotactic body radiotherapy in patients with hepatic metastases. Ann Surg Oncol 2011, 18:1081-1087.

19. Chang DT, Swaminath A, Kozak M, Weintraub J, Koong AC, Kim J, Dinniwell R, Brierley J, Kavanagh BD, Dawson LA, Schefter TE: Stereotactic body radiotherapy for colorectal liver metastases: a pooled analysis. Cancer 2011, 117:4060-4069.

20. Fumagalli I, Bibault JE, Dewas S, Kramar A, Mirabel X, Prevost B, Lacornerie T, Jerraya $H$, Lartigau E: A single-institution study of stereotactic body radiotherapy for patients with unresectable visceral pulmonary or hepatic oligometastases. Radiat Oncol 2012, 7:164. 
21. Takeda A, Kunieda E, Ohashi T, Aoki Y, Koike N, Takeda T: Stereotactic body radiotherapy (SBRT) for oligometastatic lung tumors from colorectal cancer and other primary cancers in comparison with primary lung cancer. Radiother Oncol 2011, 101(2):255-259.

22. Murakami T, Imai Y, Okada M, Hyodo T, Lee WJ, Kim MJ, Kim T, Choi BI: Ultrasonography, computed tomography and magnetic resonance imaging of hepatocellular carcinoma: toward improved treatment decisions. Oncology 2011, 81(Suppl 1):86-99.

23. Bruix J, Sherman M: Management of hepatocellular carcinoma: an update. Hepatology 2011, 53:1020-1022

24. European association for the study of the liver; European organisation for research and treatment of cancer: EASL-EORTC clinical practice guidelines: management of hepatocellular carcinoma. J Hepato/ 2012, 56:908-943.

25. Lencioni R, Llovet JM: Modified RECIST (mRECIST) assessment for hepatocellular carcinoma. Semin Liver Dis 2010, 30:52-60.

26. Tse RV, Hawkins M, Lockwood G, Kim JJ, Cummings B, Knox J, Sherman M, Dawson LA: Phase I study of individualized stereotactic body radiotherapy for hepatocellular carcinoma and intrahepatic cholangiocarcinoma. J Clin Oncol 2008, 26:657-664.

27. Chi A, Liao Z, Nguyen NP, Xu J, Stea B, Komaki R: Systemic review of the patterns of failure following stereotactic body radiation therapy in earlystage non-small-cell lung cancer: clinical implications. Radiother Oncol 2010, 94:1-11.

28. Andolino DL, Johnson CS, Maluccio M, Kwo P, Tector AJ, Zook J, Johnstone PA, Cardenes HR: Stereotactic body radiotherapy for primary hepatocellular carcinoma. Int J Radiat Oncol Biol Phys 2011, 81:e447-e453.

29. Kang JK, Kim MS, Cho CK, Yang KM, Yoo HJ, Kim JH, Bae SH, Jung da H, Kim KB, Lee DH, Han CJ, Kim J, Park SC, Kim YH: Stereotactic body radiation therapy for inoperable hepatocellular carcinoma as a local salvage treatment after incomplete transarterial chemoembolization. Cancer 2012, 118:5424-5431.

30. Blomgren H, Lax I, Näslund I, Svanström R: Stereotactic high dose fraction radiation therapy of extracranial tumors using an accelerator. Clinical experience of the first thirty-one patients. Acta Oncol 1995, 34:861-870.

31. Cardenes HR, Price TR, Perkins SM, Maluccio M, Kwo P, Breen TE, Henderson MA, Schefter TE, Tudor K, Deluca J, Johnstone PA: Phase I feasibility trial of stereotactic body radiation therapy for primary hepatocellular carcinoma. Clin Transl Oncol 2010, 12:218-225.

32. Kwon JH, Bae SH, Kim JY, Choi BO, Jang HS, Jang JW, Choi JY, Yoon SK, Chung KW: Long-term effect of stereotactic body radiation therapy for primary hepatocellular carcinoma ineligible for local ablation therapy or surgical resection. Stereotactic radiotherapy for liver cancer. BMC Cancer 2010, 10:475.

33. Louis C, Dewas S, Mirabel X, Lacornerie T, Adenis A, Bonodeau F, Lartigau E: Stereotactic radiotherapy of hepatocellular carcinoma: preliminary results. Technol Cancer Res Treat 2010, 9:479-487.

34. Seo YS, Kim MS, Yoo SY, Cho CK, Choi CW, Kim JH, Han CJ, Park SC, Lee BH, $\mathrm{Kim} \mathrm{YH}$, Lee $\mathrm{DH}$ : Preliminary result of stereotactic body radiotherapy as a local salvage treatment for inoperable hepatocellular carcinoma. J Surg Oncol 2010, 102:209-214

35. Goyal K, Einstein D, Yao M, Kunos C, Barton F, Singh D, Siegel C, Stulberg J, Sanabria J: Cyberknife stereotactic body radiation therapy for nonresectable tumors of the liver: preliminary results. HPB Surg 2010, 2010. doi: 10.1155/2010/309780.

36. Son SH, Choi BO, Ryu MR, Kang YN, Jang JS, Bae SH, Yoon SK, Choi IB, Kang KM, Jang HS: Stereotactic body radiotherapy for patients with unresectable primary hepatocellular carcinoma: dose-volumetric parameters predicting the hepatic complication. Int J Radiat Oncol Biol Phys 2010, 78:1073-1080.

37. Dawood O, Mahadevan A, Goodman KA: Stereotactic body radiation therapy for liver metastases. Eur J Cancer 2009, 45:2947-2959.

38. van Laarhoven HW, Kaanders JH, Lok J, Peeters WJ, Rijken PF, Wiering B, Ruers TJ, Punt CJ, Heerschap A, van der Kogel AJ: Hypoxia in relation to vasculature and proliferation in liver metastases in patients with colorectal cancer. Int J Radiat Oncol Biol Phys 2006, 64:473-482.
39. McCammon R, Schefter TE, Gaspar LE, Zaemisch R, Gravdahl D, Kavanagh B: Observation of a dose-control relationship for lung and liver tumors after stereotactic body radiation therapy. Int J Radiat Oncol Biol Phys 2009, 73:112-118.

40. Takeda A, Sanuki N, Eriguchi T, Kobayashi T, Iwabutchi S, Matsunaga K, Mizuno T, Yashiro K, Nisimura S, Kunieda E: Stereotactic ablative body radiotherapy for previously untreated solitary hepatocellular carcinoma. J Gastroenterol Hepatol 2013, 29:372-379.

doi:10.1186/1748-717X-9-112

Cite this article as: Yamashita et al: Local effect of stereotactic body radiotherapy for primary and metastatic liver tumors in 130 Japanese patients. Radiation Oncology 2014 9:112.

\section{Submit your next manuscript to BioMed Central and take full advantage of:}

- Convenient online submission

- Thorough peer review

- No space constraints or color figure charges

- Immediate publication on acceptance

- Inclusion in PubMed, CAS, Scopus and Google Scholar

- Research which is freely available for redistribution

Submit your manuscript at www.biomedcentral.com/submit
C) BioMed Central 